\title{
Hypo- and hypercapnia predict mortality in oxygen-dependent chronic obstructive pulmonary disease: a population-based prospective study
}

\author{
Zainab Ahmadi ${ }^{*}$, Anna Bornefalk-Hermansson ${ }^{2}$, Karl A Franklin ${ }^{3}$, Bengt Midgren ${ }^{4}$ and Magnus P Ekström,4
}

\begin{abstract}
Background: The prognostic role of the arterial blood gas tension of carbon dioxide $\left(\mathrm{PaCO}_{2}\right)$ in severe Chronic Obstructive Pulmonary Disease (COPD) remains unknown. The aim of this study was to estimate the association between $\mathrm{PaCO}_{2}$ and mortality in oxygen-dependent COPD.

Methods: National prospective study of patients starting long-term oxygen therapy (LTOT) for COPD in Sweden between October 1, 2005 and June 30, 2009, with all-cause mortality as endpoint. The association between $\mathrm{PaCO}_{2}$ while breathing air, $\mathrm{PaCO}_{2}$ (air), and mortality was estimated using Cox regression adjusted for age, sex, arterial blood gas tension of oxygen $\left(\mathrm{PaO}_{2}\right)$, World Health Organization performance status, body mass index, comorbidity, and medications.

Results: Of 2,249 patients included, 1,129 (50\%) died during a median 1.1 years (IQR 0.6-2.0 years) of observation. No patient was lost to follow-up. $\mathrm{PaCO}_{2}$ (air) independently predicted adjusted mortality $(\mathrm{p}<0.001)$. The association with mortality was U-shaped, with the lowest mortality at approximately $\mathrm{PaCO}_{2}$ (air) $6.5 \mathrm{kPa}$ and increased mortality at $\mathrm{PaCO}_{2}$ (air) below $5.0 \mathrm{kPa}$ and above $7.0 \mathrm{kPa}$.
\end{abstract}

Conclusion: In oxygen-dependent $\mathrm{COPD}, \mathrm{PaCO}_{2}$ (air) is an independent prognostic factor with a U-shaped association with mortality.

Keywords: COPD, LTOT, Mortality, PaCO 2 , Hypercapnia, Carbon dioxide, Respiratory failure, Survival

\section{Introduction}

Advanced chronic obstructive pulmonary disease (COPD) is associated with high morbidity and mortality [1]. Although long-term oxygen therapy (LTOT) decreases mortality in patients with advanced COPD and chronic hypoxemia [2,3], the prognosis is poor with a mortality rate of $51 \%$ at 2 years [4]. Predictors of mortality in oxygen-dependent COPD include sex, age, body mass index (BMI), comorbidities, forced expiratory volume in one second $\left(\mathrm{FEV}_{1}\right)$, and arterial blood gas tension of oxygen $\left(\mathrm{PaO}_{2}\right)$ [5-14].

The prognostic role of $\mathrm{PaCO}_{2}$ in oxygen-dependent COPD remains unknown. $\mathrm{PaCO}_{2}$ while breathing air, $\mathrm{PaCO}_{2}$ (air), has been associated with both increased

\footnotetext{
* Correspondence: zai.ahmd@gmail.com

'Department of Medicine, Blekinge Hospital, 37185 Karlskrona, Sweden

Full list of author information is available at the end of the article
}

mortality [5], decreased mortality [15], and no association with mortality $[4,16]$.

Defining the predictive role of $\mathrm{PaCO}_{2}$ (air) on mortality is important for several reasons. Despite the data being inconsistent, clinicians often regard hypercapnia $\left(\mathrm{PaCO}_{2}>6.5 \mathrm{kPa}\right)$ as an indicator of more severe respiratory disease, worse prognosis, and higher risk of complications from oxygen therapy including respiratory depression. High-flow oxygen given pre-hospital to patients with likely COPD exacerbation was recently associated with increased risk of acute hypercapnia and mortality [17]. Guidelines recommend titration of oxygen dose in hospital to avoid possible adverse effects when LTOT is initiated in a patient with hypercapnia [18]. Hypercapnia might indicate the presence of a concurrent hypoventilation syndrome in COPD, which is associated with shorter survival [19]. In addition, knowledge on 
predictors of mortality is needed as a prognostic model for patients with oxygen-dependent COPD is lacking.

The aim of this nationwide prospective study was therefore to estimate the association between $\mathrm{PaCO}_{2}$ (air) and mortality in oxygen-dependent COPD.

\section{Materials and methods}

We prospectively included patients from the National Register for Long Term Oxygen Therapy (Swedevox) with physician-diagnosed COPD who started LTOT between October 1, 2005 and June 30, 2009. Swedevox is a health quality register run by the health professionals and with financial support from the government. Swedevox has a population-based coverage of approximately 85\% of patients starting LTOT in Sweden since 1987 [20]. Details of the register were described in a recently published study using the same database [21]. For patients who had started LTOT more than once $(n=62)$, only the most recent treatment episode was included in the analysis. Exclusion criterion was a diagnosis of lung cancer before starting LTOT (baseline).

Data on comorbidity and time spent in hospital during the four-year period before baseline were obtained from the National Patient Register for in- and outpatient care [22]. Diagnoses were coded according to the ninth (before 1997) [23] and tenth revisions of the International Classification of Disease (ICD) [24]. Possible comorbid hypoventilation was defined as hypoxia with a normal alveolar-arterial oxygen tension difference, $\left(\mathrm{P}[\mathrm{A}-\mathrm{a}] \mathrm{O}_{2}\right)$, of $<3 \mathrm{kPa}$, or a prior diagnosis (ICD-9; ICD-10) which may cause hypoventilation [25]: scoliosis (737.4; M41), spinal muscular atrophy (335.1; G12), muscular dystrophy (335.2; G71), myasthenia gravis (358; G70), post-polio syndrome (138; G14), sequelae of poliomyelitis (B91.9), sequelae of respiratory tuberculosis (137; B90.9), obstructive sleep apnea (327.2; G47.3), obesity hypoventilation syndrome (278.0; E66.2), or prolonged mechanical ventilation (DG008, AG063; 93.90, 96.70).

Data on all dispensed drug prescriptions in outpatient care after July 1, 2005 were obtained from the Swedish Prescribed Drug Register [26]. Patients were followed until withdrawal of LTOT, death, or December 31, 2009, whichever came first. The primary endpoint was allcause mortality, obtained from the Swedish Causes of Death Register.

All patients participating in the study were informed according to directives from the authorities. The study was approved by all the relevant ethics committees in Sweden, the Swedish National Board of Health and Welfare, and the Swedish Data Inspection Board.

\section{Statistical analysis}

Baseline patient characteristics were summarized using mean with standard deviation (SD) and median with range or interquartile range (IQR) for continuous variables with normal and skewed distribution, respectively. Categorical variables were expressed as frequencies and percentages. The differences among the groups were tested with t-test for continuous variables and chisquare test for categorical variables.

Missing elements were imputed for $\mathrm{PaO}_{2}$ (air) $(\mathrm{n}=289)$, $\mathrm{PaCO}_{2}$ (air) ( $\left.\mathrm{n}=301\right), \mathrm{PaO}_{2}$ (oxygen) ( $\left.\mathrm{n}=210\right), \mathrm{PaCO}_{2}$ (oxygen) $(\mathrm{n}=213), \mathrm{FEV}_{1}(\mathrm{n}=849)$, and body mass index (BMI) $(\mathrm{n}=701)$, as previously described [21]. The model estimates were robust to the imputations. $\mathrm{P}[\mathrm{A}-\mathrm{a}] \mathrm{O}_{2}$ was calculated using the alveolar gas equation: $\mathrm{P}[\mathrm{A}-\mathrm{a}] \mathrm{O}_{2}=$ $\mathrm{P}_{\mathrm{i}} \mathrm{O}_{2}-\left(\mathrm{PaCO}_{2} / \mathrm{R}\right)-\mathrm{PaO}_{2}$. Change in $\mathrm{PaCO}_{2}$ was defined as a difference between $\mathrm{PaCO}_{2}$ (oxygen) and $\mathrm{PaCO}_{2}$ (air) of $0.3 \mathrm{kPa}$ or more.

Association between $\mathrm{PaCO}_{2}$ (air) and mortality was estimated using Cox multiple regression, adjusting for baseline age, sex, $\mathrm{PaO}_{2}$ (air), World Health Organization (WHO) performance status, BMI, number of cardiovascular diagnoses (cerebrovascular disease, heart failure, hypertension, ischemic heart disease, peripheral artery disease, pulmonary embolism, and other circulatory disease), treatment with oral glucocorticoids, benzodiazepines, and opioids. The model included a linear and a squared term for $\mathrm{PaCO}_{2}$ (air) to evaluate nonlinear associations. Higher-order terms did not improve the model with regard to diagnostics. Mortality estimates were expressed as hazard ratios (HRs) with 95\% confidence intervals (CIs). Statistical significance was defined as a two-sided p-value of $<0.05$.

Statistical analyses were conducted using the software packages Stata, version 12 (StataCorp LP; College Station, TX), and SAS, version 9.2 (SAS Institute, Inc., Cary, NC).

\section{Results}

A total of 2,249 patients were included. No patient was lost to follow-up. The cohort generated 3,118 personyears at risk during a median 1.1 years (IQR, $0.6-2.0$ years) of follow-up. During this time, 1,129 (50\%) patients died. The main causes of death were respiratory disease (68\%), cardiovascular disease (20\%), and cancer (6\%). LTOT was withdrawn for other reasons than death in 138 (6\%) patients, mainly because of improved oxygenation.

Patient characteristics at baseline are shown in Table 1. Hypercapnia $\left(\mathrm{PaCO}_{2}\right.$ (air) $\left.>6.5 \mathrm{kPa}\right)$ was present in $39 \%$ of patients. After initiating LTOT, $\mathrm{PaCO}_{2}$ increased in $45 \%$ of patients, decreased in $19 \%$, and remained unchanged (difference less than $0.3 \mathrm{kPa}$ ) in $36 \%$. Of patients with hypercapnia, 37\% increased in $\mathrm{PaCO}_{2}$ after starting LTOT, whereas $30 \%$ decreased to a $\mathrm{PaCO}_{2}$ below $6.5 \mathrm{kPa}$.

Hypercapnic patients were prescribed a slightly lower median oxygen dose than normocapnic patients, 1 (IQR, $1-1.5$ ) vs. 1.5 (IQR, 1-2) l/min ( $<0.001$ ). In total, $29 \%$ 
Table 1 Patient characteristics at baseline

\begin{tabular}{|c|c|}
\hline Characteristic & All patients, $n=2,249$ \\
\hline Age, years & $74.7 \pm 8.2$ \\
\hline Male/female gender & $921 / 1328$ \\
\hline $\mathrm{PaO}_{2}$ (air), $\mathrm{kPa}$ & $6.5 \pm 0.9$ \\
\hline $\mathrm{PaCO}_{2}$ (air), $\mathrm{kPa}$ & $6.3 \pm 1.2$ \\
\hline $\mathrm{PaO}_{2}$ (oxygen), $\mathrm{kPa}$ & $8.7 \pm 1.1$ \\
\hline $\mathrm{PaCO}_{2}$ (oxygen), $\mathrm{kPa}$ & $6.5 \pm 1.3$ \\
\hline $\mathrm{FEV}_{1}^{\dagger}$ & $0.71(0.6-1.0)$ \\
\hline Known ever to smoke, n (\%) & $2.106(94)$ \\
\hline \multicolumn{2}{|l|}{ Body mass index, n (\%) } \\
\hline$<18.5$ & $280(13)$ \\
\hline $18.5-24.9$ & $1397(62)$ \\
\hline $25-29.9$ & $338(15)$ \\
\hline$\geq 30$ & $234(10)$ \\
\hline \multicolumn{2}{|l|}{ WHO performance status, n (\%) } \\
\hline 0 & $132(6)$ \\
\hline 1 & $881(39)$ \\
\hline 2 & $714(32)$ \\
\hline 3 & $292(13)$ \\
\hline 4 & $31(1)$ \\
\hline Missing & $199(9)$ \\
\hline \multicolumn{2}{|l|}{ Cardiovascular diagnoses, n (\%) } \\
\hline 0 & $755(34)$ \\
\hline 1 & $823(37)$ \\
\hline 2 & $449(20)$ \\
\hline$>2$ & $222(10)$ \\
\hline
\end{tabular}

Data presented as mean \pm SD unless otherwise specified. Hospitalizations and diagnoses were assessed within the four-year period before the start of long-term oxygen therapy (LTOT).

${ }^{\dagger}$ Median (first quartile - third quartile).

Abbreviations: FEV 1 , forced expiratory volume in one second.

of patients started LTOT in hospital. A slightly greater proportion of patients with hypercapnia (31\%) than normocapnic patients $(27 \%)$ started LTOT in hospital $(\mathrm{p}=0.039)$.

\section{Effects on mortality}

$\mathrm{PaCO}_{2}$ (air) independently predicted adjusted mortality $(\mathrm{p}<0.001)$, as shown in Table 2 . The association with mortality exhibited a U-shaped pattern, with lowest mortality at approximately $\mathrm{PaCO}_{2}$ (air) $6.5 \mathrm{kPa}$ and increased mortality below $5.0 \mathrm{kPa}$ and above $7.0 \mathrm{kPa}$ (Figure 1). Compared to a $\mathrm{PaCO}_{2}$ (air) of $6.5 \mathrm{kPa}$, a $\mathrm{PaCO}_{2}$ (air) of $\leq 4.5 \mathrm{kPa}$ increased mortality by $17 \%$ or more, and a $\mathrm{PaCO}_{2}$ (air) of $\geq 8.0 \mathrm{kPa}$ increased mortality by at least $15 \%$. Excluding patients with possible hypoventilation $(\mathrm{n}=122)$ did not alter the estimates. Sensitivity analysis only including patients with $\mathrm{FEV} 1 / \mathrm{FVC}<0.7$ did not alter the results.
Table 2 Cox regression of all-cause mortality in 2,249 patients on long-term oxygen therapy for COPD

\begin{tabular}{|c|c|c|c|}
\hline Parameter & Hazard ratio & $95 \% \mathrm{Cl}$ & P-value \\
\hline $\mathrm{PaCO}_{2}$ (air) $\dagger$ & - & - & $<0.001$ \\
\hline Age (per y) & 1.04 & $1.03-1.05$ & $<0.001$ \\
\hline Male & 1.35 & $1.19-1.53$ & $<0.001$ \\
\hline BMI & & & $<0.001^{*}$ \\
\hline$<18.5$ & 1.35 & $1.14-1.60$ & $<0.001$ \\
\hline $18.5-24.9$ & Ref & - & - \\
\hline $25-29.9$ & 0.73 & $0.60-0.88$ & 0.001 \\
\hline$\geq 30$ & 0.80 & $0.64-1.00$ & 0.051 \\
\hline WHO performance status & & & $<0.001^{*}$ \\
\hline 0 & Ref & - & - \\
\hline 1 & 1.01 & $0.74-1.39$ & 0.927 \\
\hline 2 & 1.47 & $1.08-2.01$ & 0.016 \\
\hline 3 & 2.26 & $1.62-3.16$ & $<0.001$ \\
\hline 4 & 3.21 & $1.94-5.30$ & $<0.001$ \\
\hline Missing & 1.35 & $0.95-1.93$ & 0.098 \\
\hline $\mathrm{PaO}_{2}$ (air) (per $1 \mathrm{kPa}$ ) & 0.91 & $0.85-0.98$ & 0.014 \\
\hline Cardiovascular diagnoses & & & $<0.001^{*}$ \\
\hline 0 & Ref & - & - \\
\hline 1 & 1.25 & $1.08-1.46$ & 0.003 \\
\hline 2 & 1.42 & $1.20-1.68$ & $<0.001$ \\
\hline$>2$ & 1.38 & $1.12-1.71$ & 0.003 \\
\hline Oral glucocorticoids & 1.16 & $1.02-1.31$ & $<0.001$ \\
\hline Opioids & 1.19 & $1.05-1.35$ & 0.009 \\
\hline Benzodiazepines & 1.18 & $1.03-1.34$ & 0.014 \\
\hline
\end{tabular}

*Wald test of total significance for class variables with more than two categories. tThe $\mathrm{p}$-value is reported for both linear and squared term for $\mathrm{PaCO}_{2}$ (air). Abbreviations: $\mathrm{Cl}$, confidence interval; Ref, reference category.

$\mathrm{P}[\mathrm{A}-\mathrm{a}] \mathrm{O}_{2}$ did not predict adjusted mortality $(\mathrm{p}=0.342)$, when included instead of $\mathrm{PaO}_{2}$ and $\mathrm{PaCO}_{2}$. Changes in $\mathrm{PaCO}_{2}$ when starting LTOT did not affect adjusted mortality; neither a rise in $\mathrm{PaCO}_{2}(\mathrm{p}=0.227)$ or a fall in $\mathrm{PaCO}_{2}(\mathrm{p}=0.355)$.

\section{Discussion}

The novel finding in the present study is that $\mathrm{PaCO}_{2}$ (air) has an U-shaped association with mortality in oxygen-dependent COPD. $\mathrm{PaCO}_{2}$ (air) values lower than $5.0 \mathrm{kPa}$ and higher than $7.0 \mathrm{kPa}$ were associated with increased mortality.

Previous findings on the association between $\mathrm{PaCO}_{2}$ and mortality have been conflicting. Our results are consistent with studies reporting increased mortality associated with either hypocapnia [5,27] or hypercapnia $[3,28,29]$. In a large study of COPD patients on LTOT, Chailleux et al. found $\mathrm{PaCO}_{2}$ to be an independent negative predictor at 3 years follow-up [5]. However, Aida and colleagues found no association between 


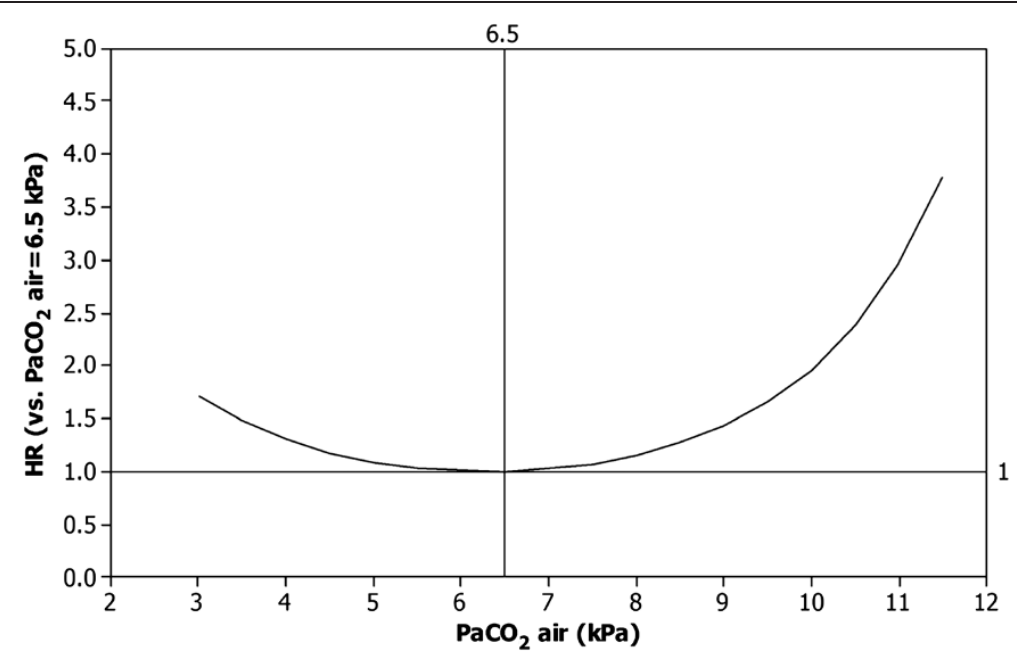

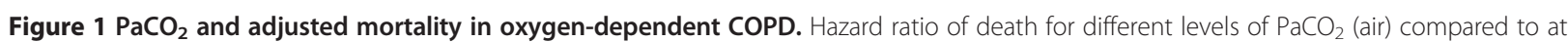
$\mathrm{PaCO}_{2}$ (air) $=6.5 \mathrm{kPa}$, adjusted for age, sex, $\mathrm{PaO}_{2}$ (air), WHO performance status, BMl, number of cardiovascular diagnoses, and treatment with oral glucocorticoids, benzodiazepines and opioids. Abbreviations: $\mathrm{PaCO}_{2}$ (air), Arterial blood gas tension of carbon dioxide on air; $\mathrm{PaO}_{2}$ (air), Arterial blood gas tension of oxygen on air; WHO, World Health Organization; BMI, Body Mass Index.

$\mathrm{PaCO}_{2}$ (air) and mortality [16]. As none of the previous studies, to our knowledge, evaluated the shape of the association, the discrepancy between the findings of previous studies may partly owe to that they did not account for a nonlinear association.

Strengths of the present study include its national prospective design and that it included a large cohort of both men and women with oxygen-dependent COPD. No patient was lost to follow-up. The analysis was adjusted for relevant confounders, including comorbidity and exposure to benzodiazepines and opioids. A limitation of the study is that we lacked data on $\mathrm{pH}$ and base excess and could not evaluate the chronicity of the respiratory failure or the level of metabolic compensation. Nevertheless, the study presents data on the prognostic role of $\mathrm{PaCO}_{2}$ in patients starting LTOT for COPD that are likely to be applicable to current clinical practice.

An interesting additional finding was the large variability in the change in $\mathrm{PaCO}_{2}$ when starting LTOT. There is concern among clinicians that the level of $\mathrm{PaCO}_{2}$ will increase after starting LTOT, especially in hypercapnic patients. In the present study, $30 \%$ of patients with hypercapnia actually decreased their $\mathrm{PaCO}_{2}$ to below $6.5 \mathrm{kPa}$ after initiation of LTOT and $\mathrm{PaCO}_{2}$ remained unchanged in $36 \%$ of patients. This may be explained by regression to the mean and by improving blood gases over time in patients starting LTOT in relation to an exacerbation. The change in $\mathrm{PaCO}_{2}$ between breathing room air and breathing oxygen (LTOT) did not predict mortality. This suggests that some increase in $\mathrm{PaCO}_{2}$ from baseline when starting LTOT is well-tolerated and not associated with worse prognosis.
Which mechanisms underpin the association between blood gas disturbances and mortality? The lack of a clear association between $\mathrm{P}[\mathrm{A}-\mathrm{a}] \mathrm{O}_{2}$ and mortality implies that gas exchange inefficiency is not the main driver behind the increased mortality associated with hypoxemia and hypo- and hypercapnia. Our study suggests that the level of alveolar ventilation predicts mortality independently of the level of hypoxemia. Factors contributing to the increasing mortality could include more severe underlying COPD, respiratory maladaptation, and the presence of comorbidities. In hypocapnia, increased minute ventilation may cause respiratory muscle fatigue, hastened ventilatory failure and death. This might reflect a relative inability among these patients to adapt their breathing pattern to avoid respiratory muscle fatigue. Comorbidities such as congestive heart failure or pulmonary embolism may also contribute to the increased ventilation and worse prognosis. Modest hypercapnia may reflect an adaptive alveolar hypoventilation, which occurs (unconsciously) to minimize dyspnea and respiratory muscle fatigue. While modest hypercapnia were not associated with earlier death, $\mathrm{PaCO}_{2}$ (air) exceeding $7.0 \mathrm{kPa}$ seemed to be maladaptive and associated with increased mortality rates. Mechanical defects of the chest wall, such as kyphoscoliosis, and hyperinflation may predispose to alveolar hypoventilation by imposing additional work on the inspiratory muscles [30]. Concurrent hypoventilation syndrome may contribute to hypercapnia in some COPD patients, requiring treatment with home mechanical ventilation in addition to oxygen therapy [31]. However, it is still unclear whether long-term non-invasive home ventilation improves prognosis in patients with stable hypercapnic COPD [32]. 
For clinicians, this study suggests that patients with $\mathrm{PaCO}_{2}$ (air) below $5 \mathrm{kPa}$ or above $7 \mathrm{kPa}$ are at increased risk of death and should be optimally treated and carefully followed. Furthermore, patients with hypo- or hypercapnia should be evaluated for comorbid diseases, including heart failure and hypoventilation syndromes. The U-shaped association of $\mathrm{PaCO}_{2}$ (air) with overall mortality should be validated by further studies and incorporated in future prognostic models of patients with advanced COPD.

\section{Conclusion}

In conclusion, the level of alveolar ventilation, as reflected by both hypo- and hypercapnia, predicts mortality in oxygen-dependent COPD.

\section{Abbreviations}

BMl: Body mass index; Cl: Confidence interval; COPD: Chronic obstructive pulmonary disease; HR: Hazard ratio; ICD: International classification of disease; IQR: Interquartile range; $\mathrm{FEV}_{1}$ : Forced expiratory volume in one second; LTOT: Long-term oxygen therapy; $\mathrm{P}[\mathrm{A}-\mathrm{a}] \mathrm{O}_{2}$ : Alveolar-arterial oxygen tension difference; $\mathrm{PIO}_{2}$ : Inspired partial pressure of oxygen; R: Respiratory quotient, normally $0.8 ; \mathrm{PaO}_{2}$ : Arterial blood gas tension of oxygen; $\mathrm{PaCO}_{2}$ : Arterial blood gas tension of carbon dioxide; $\mathrm{PaO}_{2}$ (air): Arterial blood gas tension of oxygen on air; $\mathrm{PaO}_{2}$ (oxygen): Arterial blood gas tension of oxygen on oxygen; $\mathrm{PaCO}_{2}$ (air): Arterial blood gas tension of carbon dioxide on air; $\mathrm{PaCO}_{2}$ (oxygen): Arterial blood gas tension of carbon dioxide on oxygen; Ref: Reference category; SD: Standard deviation; WHO: World health organization.

\section{Competing interests}

The authors declare that they have no competing interest.

\section{Authors' contributions}

ME had full access to all the data in the study and takes full responsibility for the integrity of the data and the accuracy of the data analysis. Conception and design: $\mathrm{ABH}, \mathrm{ME}, \mathrm{ZA}$; acquisition of data: $\mathrm{BM}, \mathrm{ME}$; analysis and interpretation of data: $A B H, B M, K F, M E, Z A$; drafting the article: $A B H, M E, Z A$; revision for important intellectual content and approval of the version to be published: $A B H, B M, K F, M E, Z A$. All authors read and approved the final manuscript.

\section{Acknowledgements}

The work was carried out at the Department of Respiratory Medicine, Blekinge Hospital Karlskrona, University of Lund, Sweden. We thank Kerstin Ström for being a constant inspiration and all the physicians and nurses who collected the data and cared for the patients.

\section{Funding}

This study was funded by the Research Council of Blekinge, the Swedish Heart-Lung Foundation, and the Swedish National Board of Health and Welfare.

\section{Author details}

${ }^{1}$ Department of Medicine, Blekinge Hospital, 37185 Karlskrona, Sweden. ${ }^{2}$ Uppsala Clinical Research Center, Uppsala University Hospital, Uppsala, Sweden. ${ }^{3}$ Department of Surgical and Perioperative Sciences, Surgery, University Hospital of Umeå, Umeå, Sweden. ${ }^{4}$ Department of Clinical Sciences, Lund, Division of Respiratory Medicine \& Allergology, Lund University Hospital, Lund, Sweden.

Received: 4 September 2013 Accepted: 6 March 2014 Published: 13 March 2014

\section{References}

1. Global Strategy for the Diagnosis, Management and Prevention of COPD, Global Initiative for Chronic Obstructive Lung Disease (GOLD) 2011. In 2011. Available from http://www.goldcopd.org/.
2. Nocturnal Oxygen Therapy Trial Group: Continuous or nocturnal oxygen therapy in hypoxemic chronic obstructive lung disease: a clinical trial. Ann Intern Med 1980, 93:391-398.

3. Report of the Medical Research Council Working Party: Long term domiciliary oxygen therapy in chronic hypoxic cor pulmonale complicating chronic bronchitis and emphysema. Lancet 1981, 1:681-686.

4. Crockett AJ, Cranston JM, Moss JR, Alpers JH: Survival on long-term oxygen therapy in chronic airflow limitation: from evidence to outcomes in the routine clinical setting. Intern Med J 2001, 31:448-454.

5. Chailleux E, Fauroux B, Binet F, Dautzenberg B, Polu JM: Predictors of survival in patients receiving domiciliary oxygen therapy or mechanical ventilation. A 10-year analysis of ANTADIR Observatory. Chest 1996, 109:741-749.

6. Dolan S, Varkey B: Prognostic factors in chronic obstructive pulmonary disease. Curr Opin Pulm Med 2005, 11:149-152.

7. Costello R, Deegan P, Fitzpatrick M, McNicholas WT: Reversible hypercapnia in chronic obstructive pulmonary disease: a distinct pattern of respiratory failure with a favorable prognosis. Am J Med 1997, 102:239-244.

8. Celli BR: Predictors of mortality in COPD. Respir Med 2010, 104:773-779.

9. Budweiser S, Jorres RA, Riedl T, Heinemann F, Hitzl AP, Windisch W, Pfeifer M: Predictors of survival in COPD patients with chronic hypercapnic respiratory failure receiving noninvasive home ventilation. Chest 2007, 131:1650-1658.

10. Anthonisen NR: Home oxygen therapy in chronic obstructive pulmonary disease. Clin Chest Med 1986, 7:673-678.

11. Miyamoto K, Aida A, Nishimura M, Aiba M, Kira S, Kawakami Y: Gender effect on prognosis of patients receiving long-term home oxygen therapy. The respiratory failure research group in Japan. Am J Respir Crit Care Med 1995, 152:972-976.

12. Nizet TA, van den Elshout FJ, Heijdra YF, van de Ven MJ, Mulder PG, Folgering HT: Survival of chronic hypercapnic COPD patients is predicted by smoking habits, comorbidity, and hypoxemia. Chest 2005, 127:1904-1910.

13. Strom K, Boman G: Long-term oxygen therapy in parenchymal lung diseases: an analysis of survival. The Swedish Society of Chest Medicine. Eur Respir J 1993, 6:1264-1270.

14. Oga T, Nishimura $K$, Tsukino M, Sato S, Hajiro T: Analysis of the factors related to mortality in chronic obstructive pulmonary disease: role of exercise capacity and health status. Am J Respir Crit Care Med 2003, 167:544-549.

15. Dubois P, Jamart J, Machiels J, Smeets F, Lulling J: Prognosis of severely hypoxemic patients receiving long-term oxygen therapy. Chest 1994, 105:469-474.

16. Aida A, Miyamoto K, Nishimura M, Aiba M, Kira S, Kawakami Y: Prognostic value of hypercapnia in patients with chronic respiratory failure during long-term oxygen therapy. Am J Respir Crit Care Med 1998, 158:188-193.

17. Austin MA, Wills KE, Blizzard L, Walters EH, Wood-Baker R: Effect of high flow oxygen on mortality in chronic obstructive pulmonary disease patients in prehospital setting: randomised controlled trial. BMJ 2010, 341:c5462.

18. The Swedish national register for patients on Long Term Oxygen Therapy and Home Mechanical Ventilation (Swedevox). In Available from http://www.ucr.uu.se/swedevox/index.php. [http://www.ucr.uu.se/swedevox/]

19. Marin JM, Soriano JB, Carrizo SJ, Boldova A, Celli BR: Outcomes in patients with chronic obstructive pulmonary disease and obstructive sleep apnea: the overlap syndrome. Am J Respir Crit Care Med 2010, 182:325-331.

20. Strom K, Boe J: A national register for long-term oxygen therapy in chronic hypoxia: preliminary results. Eur Respir J 1988, 1:952-958.

21. Ekstrom MP, Bornefalk Hermansson A, Strom KE: Effects of cardiovascular drugs on mortality in severe chronic obstructive pulmonary disease: a time-dependent analysis. Am J Respir Crit Care Med 2013, 187(7):715-720.

22. Swedish National Board of Health and Welfare: Quality and Contents of the Swedish Hospital Discharge Register. Stockholm: Swedish National Board of Health and Welfare. The Center for Epidemiology; 2008.

23. World Health Organization: Manual of the International Classification of Diseases, Injuries and Causes of Death. 9th revision., vol. 1. Geneva, Switzerland: World Health Organization; 1978.

24. World Health Organization: Manual of the International Statistical Classification of Diseases and Health Related Problems. 10th revision., vol. 1 Geneva, Switzerland: World Health Organization; 1992.

25. Duffin J, Phillipson E: Hypo and hyperventilation syndromes. In Murray and Nadel's Textbook of Respiratory Medicine. Edited by Mason R, Broaddus 
CV, Martin T, King T Jr, Scharaufnagel D, Murray J. JA N. Philadelphia: Saunders; 2010:1859-1880.

26. Wettermark B, Hammar N, Fored CM, Leimanis A, Otterblad Olausson P, Bergman U, Persson I, Sundstrom A, Westerholm B, Rosen M: The new Swedish Prescribed Drug Register-opportunities for pharmacoepidemiological research and experience from the first six months. Pharmacoepidemiol Drug Saf 2007, 16:726-735.

27. Lima DF, Dela Coleta K, Tanni SE, Silveira LV, Godoy I, Godoy I: Potentially modifiable predictors of mortality in patients treated with long-term oxygen therapy. Respir Med 2011, 105:470-476.

28. Cooper CB, Waterhouse J, Howard P: Twelve year clinical study of patients with hypoxic cor pulmonale given long term domiciliary oxygen therapy. Thorax 1987, 42:105-110.

29. Foucher P, Baudouin N, Merati M, Pitard A, Bonniaud P, Reybet-Degat $\mathrm{O}$, Jeannin $L$ : Relative survival analysis of 252 patients with COPD receiving long-term oxygen therapy. Chest 1998, 113:1580-1587.

30. Roussos C, Koutsoukou A: Respiratory failure. Eur Respir J Suppl 2003, 47:3s-14s.

31. Gustafson T, Franklin KA, Midgren B, Pehrsson K, Ranstam J, Strom K: Survival of patients with kyphoscoliosis receiving mechanical ventilation or oxygen at home. Chest 2006, 130:1828-1833.

32. Struik FM, Lacasse Y, Goldstein R, Kerstjens HM, Wijkstra PJ: Nocturnal non-invasive positive pressure ventilation for stable chronic obstructive pulmonary disease. Cochrane Database Syst Rev 2013, 6:CD002878.

doi:10.1186/1465-9921-15-30

Cite this article as: Ahmadi et al:: Hypo- and hypercapnia predict mortality in oxygen-dependent chronic obstructive pulmonary disease: a population-based prospective study. Respiratory Research 2014 15:30.

\section{Submit your next manuscript to BioMed Central and take full advantage of:}

- Convenient online submission

- Thorough peer review

- No space constraints or color figure charges

- Immediate publication on acceptance

- Inclusion in PubMed, CAS, Scopus and Google Scholar

- Research which is freely available for redistribution 